\title{
Problematic Online Behaviors among Adolescents and Emerging Adults: Associations between Cyberbullying Perpetration, Problematic Social Media Use, and Psychosocial Factors
}

\author{
Kagan Kurcaburun $^{1}$ • Constantinos M. Kokkinos ${ }^{2}$. \\ Zsolt Demetrovics ${ }^{3}$ - Orsolya Király ${ }^{3}$. \\ Mark D. Griffiths ${ }^{4}$ • Tuğba Seda Çolak ${ }^{1}$
}

Published online: 31 May 2018

(C) The Author(s) 2018

\begin{abstract}
Over the past two decades, young people's engagement in online activities has grown markedly. The aim of the present study was to examine the relationship between two specific online behaviors (i.e., cyberbullying perpetration, problematic social media use) and their relationships with social connectedness, belongingness, depression, and self-esteem among high school and university students. Data were collected from two different study groups via two questionnaires that included the Cyberbullying Offending Scale, Social Media Use Questionnaire, Social Connectedness Scale, General Belongingness Scale, Short Depression-Happiness Scale, and Single Item Self-Esteem Scale. Study 1 comprised 804 high school students (48\% female; mean age 16.20 years). Study 2 comprised 760 university students ( $60 \%$ female; mean age 21.48 years). Results indicated that problematic social media use and cyberbullying perpetration (which was stronger among high school students) were directly associated with each other. Belongingness (directly) and social connectedness (indirectly) were both associated with cyberbullying perpetration and problematic social media use. Path analysis demonstrated that while age was a significant direct predictor of problematic social media use and cyberbullying perpetration among university students, it was not
\end{abstract}

\section{Mark D. Griffiths}

mark.griffiths@ntu.ac.uk

Faculty of Education, Duzce University, Duzce, Turkey

2 School of Education Sciences, Democritus University of Thrace, Alexandroupolis, Greece

3 Institute of Psychology, ELTE Eötvös Loránd University, Budapest, Hungary

4 International Gaming Research Unit, Psychology Department, Nottingham Trent University, 50 Shakespeare Street, Nottingham NG1 4FQ, UK 
significant among high school students. In both samples, depression was a direct predictor of problematic social media use and an indirect predictor of cyberbullying perpetration. However, majority of these associations were relatively weak. The present study significantly adds to the emerging body of literature concerning the associations between problematic social media use and cyberbullying perpetration.

Keywords Cyberbullying perpetration - Problematic social media use - Social connectedness · Belongingness $\cdot$ Depression $\cdot$ Self-esteem

Recent developments have made the relationship between individuals, technology, and technological devices much closer. Although the Internet does not have a long history, it has become indispensable in contemporary day-to-day life. Nowadays, social media platforms are the most popular and widely used applications used on the Internet (Kemp 2017). According to the Internet usage results report of Wearesocial and Hootsuite digital marketing agency published in January 2017, the number of active social media users has increased by $21 \%$ all over the world compared with the previous year (Kemp 2017). Although social media is used for positive purposes such as meeting new people and socializing, maintaining existing relationships, and informational and educational purposes (Horzum 2016), some individuals (including high-risk groups such as students) demonstrate problematic online behaviors that may negatively affect them (Kuss et al. 2014). Cyberbullying perpetration (CBP) and problematic social media use (PSMU) are considered two such potential risky behaviors (Ayas et al. 2016). Using the problem behavior theory (PBT), the present study examines the relationship between PSMU and CBP and their relationships to social connectedness, general belongingness, depression, and self-esteem among high school and university students.

\section{Problematic Social Media Use}

Social media applications have become increasingly popular on the Internet. According to the Household Information Technologies Usage Rates reported by the Turkish Statistical Institute (Turkstat 2016), social media use is the most popular activity engaged in by individuals online $(82.4 \%)$. Furthermore, a minority of social media users appears to be problematic users of these platforms and some individuals appear not to be able to control themselves (Kuss and Griffiths 2017). Despite the inconsistency on the definition of problematic social media use (PSMU) (Bányai et al. 2017), based on the biopsychosocial theoretical model, PSMU comprises mood changes and total preoccupation of using social media, having negative feelings and psychological symptoms when social media is unavailable, and having negative consequences in real-life areas because of excessive social media use (Bányai et al. 2017).

\section{Cyberbullying Perpetration}

Another problem behavior that is related to Internet technology is cyberbullying perpetration (CBP). CBP is defined as the use of Wi-Fi-enabled devices such as computers, tablets, and mobile phones by a person or group of people with the purpose of intentionally and repetitively behaving in a hostile way to harm the others (Hinduja and Patchin 2014). Losing 
control while using the Internet increases the probability of risky online behaviors such as CBP (Gámez-Guadix et al. 2016). CBP, which is reported as being frequent during adolescence (Yen et al. 2014), is a serious problem that affects $20-40 \%$ of young people (Tokunaga 2010). CBP appears to continue in adulthood but starts to decline during late adolescence (Antoniadou and Kokkinos 2015). The fact that cyberbullying perpetrators do not need to know their victim and do not see the results of their actions are among the factors that can increase the frequency of CBP (Campbell et al. 2013). Digital platforms where individuals are most exposed to or demonstrate CBP are via instant messaging and social media (Whittaker and Kowalski 2015).

\section{Problem Behavior Theory}

Jessor (1987) reported that problematic behaviors among adolescents such as committing crime and substance abuse originate from permanent characteristics of the individual, rather than an instant characteristic. In order to understand such problematic behaviors, research should focus on the interrelated factors of personality, perceived environment, and behavioral systems (Jessor 1991). A number of years later, Boyd et al. (2009) extended the conceptual model of PBT and asserted problematic behaviors should be understood in terms of an individual's social and perceived environment, demographic characteristics, genetic/ biological factors, and psychological characteristics including personality factors.

The problem behavior theory (PBT) can also be applied to problematic internet use. Many scholars have intuitively referred to the features of PBT in their accounts of pathological internet use without reference to the PBT specifically (e.g., Griffiths [2005] biopsychosocial model of addiction that also includes structural characteristics of the activity and the situational characteristics of the surrounding environment in which the behavior takes place). Over the past two decades, many scholars have adapted various incarnations of the DSM criteria for the pathological gambling and/or psychoactive substance abuse (see Kuss et al. 2014 for a review). When clinically assessed, addictions often represent the attempt of an individual to control depression and anxiety, while reflecting deep insecurities and the feeling of inner emptiness (Kim et al. 2006). In this context, based on the definitions of PBT, PSMU and CBP described above, PSMU and CBP can be considered as bearing the characteristics of potentially problematic online behaviors.

Despite the fact that the association between CBP and PSMU has yet to be empirically examined, previous research has reported an association between problematic Internet use and CBP among students (Casas et al. 2013; Eksi 2012; Kurcaburun and Baștug 2016). Consequently, the present authors hypothesize that CBP and PSMU are positively related. Furthermore, spending excessive time in platforms where problematic social interactions may occur is also likely to increase the probability of CBP. Kopecký (2014) suggested that social media platforms are where cyberbullying incidents are likely to occur.

Previous studies have also indicated that when problematic online behaviors are considered, gender is an important control variable. Female and male students have different usage aims, habits, and behaviors in online contexts (Kuss and Griffiths 2017). Furthermore, several studies have shown that female students are more prone to depressive moods (NolenHoeksema and Girgus 1994), and to develop problematic use of online platforms containing higher social interactions (Andreassen et al. 2017). Based on recent previous studies (Andreassen et al. 2017; Kurcaburun and Tosuntaş 2017), it is hypothesized that females will 
demonstrate less CBP and more PSMU and depression. Age is another important control variable concerning CBP and PSMU. Several studies have shown that younger emerging adults and older adolescent students are more prone to depressive moods (Bayram and Bilgel 2008; Hankin et al. 2015), and therefore they may experience problematic online behaviors in to cope with the maladaptive depression. Furthermore, it has been suggested that depressive feelings and problematic behaviors may peak around the last years of high school (Bayram and Bilgel 2008; Hankin et al. 2015). Based on previous studies (Andreassen et al. 2017; Ševčíková and Šmahel 2009), it is hypothesized that younger emerging adults and older adolescent students will be more problematic social media users and cyberbullying perpetrators.

\section{Self-Esteem and Depression}

Individuals' PSMU, which is arguably a "pure" form of Internet addiction or sub-type of Internet addiction because there is no offline equivalent (Kuss and Griffiths 2011, 2017), have similar symptoms to the deprivation symptoms of substance abuse. For instance, in a study carried out by Woods and Scott (2016) with Scottish adolescents, it was found that the teenagers emotionally invested too much in social media during night and day, had low sleep quality, low self-esteem, high anxiety, and high depression levels. This may mean that if adolescents are not connected to social media, they may feel isolated and stressed, and may lead to increased anxiety and depression (Woods and Scott 2016). These symptoms can arguably be considered as indicators of deprivation. Various studies have shown that those operationally defined as addicted to Internet activities have low levels of self-esteem (Chang et al. 2015; Perrella and Caviglia 2017), and that positive or negative feedback to their online posts can affect their levels of self-esteem (Valkenburg et al. 2006). Individuals use social media platforms for many reasons, including (among others) seeking social support, appeasing their emotions, and coping with depressed psychological status. However, sometimes social media platforms have the opposite effects than to what is desired. For example, depressed individuals with low self-esteem share posts that reflect their negative psychological status to receive support from others, and if this behavior does not result in receiving the desirable reactions they may feel worse (Forest and Wood 2012). The use of social media as a means to increase self-esteem may, on the contrary, cause their self-esteem to decrease due to CBP (Patchin and Hinduja 2010; Radovic et al. 2015).

In sum, depression - which is strongly related to self-esteem (Orth et al. 2008) - is an important construct that affects life satisfaction and psychological wellbeing, as well as influencing online behaviors among adolescents and young adults. Previous studies have demonstrated that PSMU and CBP are positively related to depression (Campbell et al. 2013; Chang et al. 2015; Fan et al. 2016; Jung et al. 2014; Kurcaburun 2016). Based on these studies, it is hypothesized that depression will positively predict CBP and PSMU. According to PBT, low self-esteem is among the personality risk factors that may lead to development of problem behaviors (Jessor 1991). Moreover, previous studies suggest that students with low self-esteem demonstrate more PSMU and CBP (Andreassen et al. 2017; Fan et al. 2016). Therefore, it is hypothesized that self-esteem will be negatively associated with CBP and PSMU. Moreover, moving from the vulnerability model indicating that self-esteem is a strong predictor to onset and maintenance of depression (Orth et al. 2008), it is hypothesized that depression will mediate the association of self-esteem with PSMU and CBP. 


\section{Social Connectedness and Belongingness}

Many Internet behaviors are social behaviors. Research has shown that factors such as cohesive family environment and caring adults - which are considered among the social and perceived environmental dimensions of the PBT (Jessor 1991) - decrease the engagement in problem behaviors (e.g., O'Connor et al. 2016). Some of the social needs that cannot be met in everyday life such as social connectedness (SC) and general belonging (GB) can be met in the virtual environment via social media platforms, and this may affect the frequency of social media use. SC was defined by Lee and Robbins (1995) as a sense of belonging that individuals feel towards their peers and society they live in and is derived from one's relationship experiences with one's surroundings. GB was defined by Hagerty et al. (1992) as "the experience of personal involvement in a system or environment so that persons feel themselves to be an integral part of that system or environment" (p. 173). SC and GB are considered as some of the most important social needs for individuals to build up and maintain relationships (e.g., Hagerty et al. 1996; Lee and Robbins 1995). Previous studies found that individuals who grow up with the feeling of low SC become outsiders and disconnected from society (Lee and Robbins 2000). Such individuals are also likely to have low self-esteem, build unsatisfactory relationships, and lack social identity (Lee and Robbins 1998). SC, which is negatively associated with loneliness, social discomfort, social distress, and depression (Lee et al. 2001), plays a vital role on adolescents' lives and psychosocial development. Individuals, particularly during adolescence, need and search to connect to their peers and loved ones (Wu et al. 2016). Students with higher SC report more subjective wellbeing (Jose et al. 2012) and maintain a healthier development. Moreover, lower GB is related to many negative factors that are related to psychological wellbeing of students, such as lower SC, happiness, and life satisfaction, as well as higher loneliness, depression, avoidant and ambivalent attachment styles, neuroticism, and introversion (Malone et al. 2012).

Being online in social media platforms, which is perceived as a type of socialization, can provide individuals with the feeling of belonging (Ylldırım 2014). Individuals' impetus to seek out long-term satisfying relationships can be a motivation for their emotions, thoughts, and behaviors. Because short-term relationships do not satisfy human beings in the long run, individuals seek out relationships that meet their need of belonging (Baumeister and Leary 1995). Individuals, who have the need to live in a community, may also satisfy their need for a safe and predictable community environment via social media sites (Griffiths et al. 2014). In other words, in case of individuals who have few social connections in their real life, the Internet is the place where they can coexist with other people and restore their damaged social self (Eroğlu 2016). Meeting new people via social media and building new friendships make individuals feel less lonely and more supported (Shaw and Gant 2002).

Online relationships are often regarded as closer, more secure, and less intimidating than real-life friendships, and they can reduce the perceived loneliness in the lives of the addicts (Young 1998). Kim et al. (2013) reported that problematic Internet use was three times more prevalent among students at the end of an 18-month period compared to their first days at university, and that this increase was due to psychosocial factors such as depression and life dissatisfaction. In other words, an individual typically becomes a problematic social media user in order to cope with the real-life problems. However, Ellison et al. (2007) demonstrated that the friendships created via social media platforms are not close friendships. There are also studies showing that social media use predicts perceived social support and happiness in a negative way (Çolak and Doğan 2016; Moody 2001; Sum et al. 2008), although there are 
some studies suggesting that individuals use social media platforms to meet their social support needs (Amichai-Hamburger and Ben-Artzi 2003). The present study used the separate constructs of social connectedness and general belongingness with two different samples (i) because the social connectedness assessment tool that was used in the study was developed in order to assess adolescents' levels of social connectedness while general belongingness scale was developed for individuals that are aged 18 years and above, and (ii) despite the fact that they appear to be different concepts, social connectedness and general belongingness overlap and are very strongly correlated (Malone et al. 2012). Thus, the present study investigated the variation of these concepts' relationships among two different samples by offering two separate complex models.

\section{The Present Studies}

The present study offered a complex mediaton model with the variables that were previously shown to be related. This was in order to bring a more detailed explanation concerning the effects of these variables, and to include some variables that have not previously been empirically shown to be associated. Several hypotheses were constructed from the aforementioned studies. Based on recent previous studies (Andreassen et al. 2017; Kurcaburun and Tosuntaş 2017), it is hypothesized that females will demonstrate less CBP and more PSMU. Based on previous studies (Andreassen et al. 2017; Ševčíková and Šmahel 2009), it is also hypothesized that younger students will be more problematic social media users and cyberbullying perpetrators. Based on PBT and existing literature, it is hypothesized that depression and low self-esteem will be positively associated with CBP and PSMU, and depression will mediate the association of self-esteem with PSMU and CBP. Utilizing PBT (Jessor 1991) and previous studies associating loneliness with PSMU (Griffiths et al. 2014), it is hypothesized that students with lower sense of SC and GB will report higher PSMU and CBP. Moreover, since decreased feelings of SC and GB have been reported to increase depressive symptoms (Lee et al. 2001; Malone et al. 2012), it is hypothesized that depression will mediate the effect of SC and GB on CBP and PSMU (see Fig. 1).

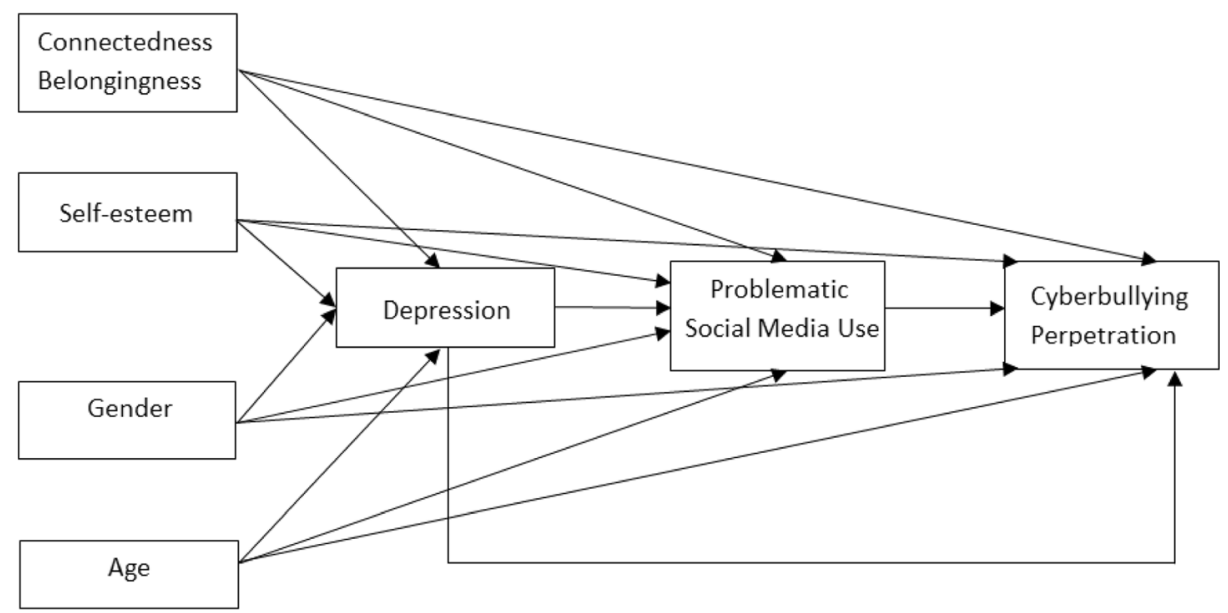

Fig. 1 Hypothesized model 


\section{Method (Study 1): Relationships between CBP, PSMU, SC, Depression, and Self-Esteem}

The goal of study 1 was to examine the relationships between CBP, PSMU, SC, depression, and self-esteem among high school students using a structural equation model (see Fig. 1 for the hypothesized model).

\section{Participants}

A total of 1143 students participated in study 1 . In the first step, 339 high school and university students $\left(29 \%\right.$ female; $M_{\text {age }}=17.96$ years, $\left.\mathrm{SD}=2.46\right)$ were used for adaptation of the Cyberbullying Offending Scale (CBOS) and the Short Depression-Happiness Scale (SDHS) into Turkish. In the second step, a convenience sample of 804 students aged between 14 and 21 years from five different high schools ( $48 \%$ female; $M_{\mathrm{age}}=16.20$ years, $\mathrm{SD}=1.03$ ), filled out the questionnaires. Researchers gathered the data by visiting each school, giving the necessary information, and handing out the questionnaires to students. Students participated in the study voluntarily and anonymously.

\section{Measures}

Cyberbullying Offending Scale (CBOS) The CBOS assesses the level of different types of cyberbullying perpetration behaviors, comprising nine items (e.g., "I spread rumors about someone online") on a five-point Likert scale from "never" to "several times." It was developed by Patchin and Hinduja (2015) and adapted to Turkish by the researchers. After introducing the error covariances in the model, suggested by the modification indices, confirmatory factor analysis (CFA) of CBOS generated acceptable fit values for the unidimensional factor structure $\left(\chi^{2} / \mathrm{df}=2.86, \mathrm{RMSEA}=0.07(\mathrm{CI} 90 \%(0.05,0.10))\right.$, $\mathrm{SRMR}=0.03$, $\mathrm{CFI}=0.98, \mathrm{NFI}=0.97$, GFI $=0.96, \mathrm{IFI}=0.98$ ). The Cronbach's alpha in the Turkish validation of the scale was 0.89 . Analyses indicated that Turkish form of the CBOS was valid and

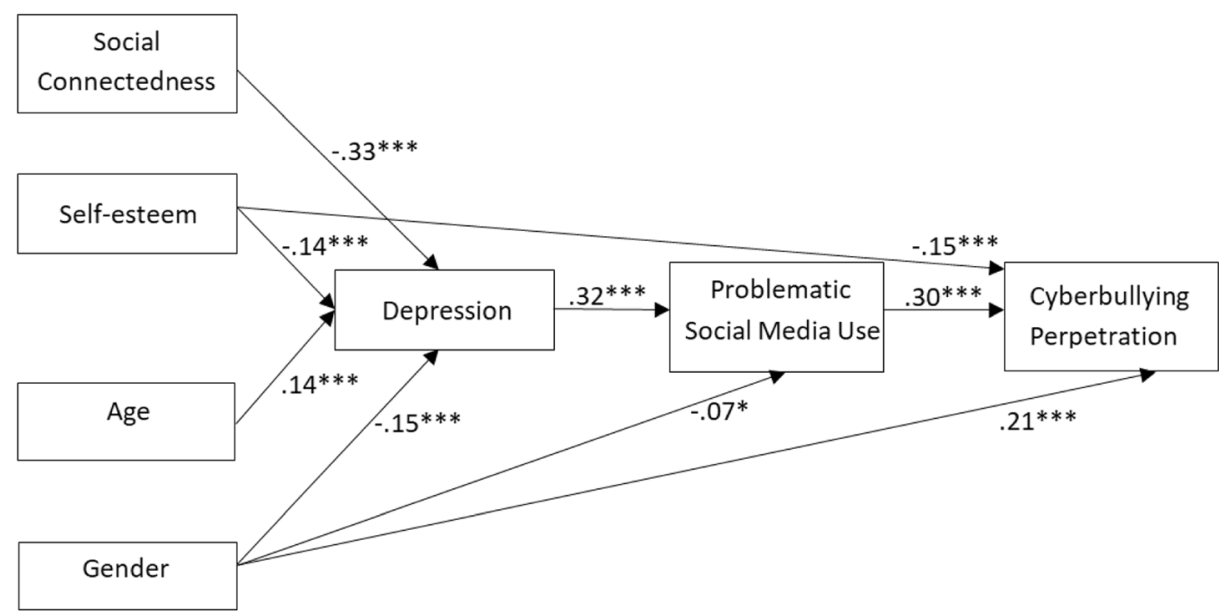

Fig. 2 Final model of the significant path coefficients of study 1. For clarity, the correlations between the four independent variables have not been depicted in the figure 
reliable for assessing high school and university students' cyberbullying perpetration levels. Cronbach's alpha of the scale in study 1 was 0.87 .

Social Media Use Questionnaire (SMUQ) The SMUQ scale assesses problematic and excessive use of social media, comprising nine items (e.g., "I feel anxious, when I am not able to check my social network account") on a five-point Likert scale from "never" to "always," with two factors which are withdrawal and compulsion. It was developed by Xanidis and Brignell (2016) and adapted to Turkish in a previous study (Kircaburun et al. 2018). The Cronbach's alpha for the total scale in validation of the Turkish form was 0.90 . In study 1 , Cronbach's alpha of the total scale was 0.83 .

Social Connectedness Scale (SCS) The SCS assesses feeling of belonging among adolescents aged between 14 and 18 years (Lee and Robbins 1995). It comprises eight items (e.g., "I do not feel that I participate with anyone or any group") on a six-point Likert scale ranging from "absolutely disagree" to "absolutely agree." It was adapted to Turkish by Duru (2007). Reported Cronbach's alpha for the original Turkish validation was 0.90 , and in the present study it was 0.89 .

Short Depression-Happiness Scale (SDHS) The original SDHS was developed by Joseph et al. (2004). CFA was used to test the proposed one-factor structure of the scale on the Turkish sample. However, the analysis provided poor fit indices. Therefore, exploratory factor analysis (EFA) was carried out. According to the EFA, the Turkish form of the scale comprised of two sub-scales, depression and happiness, with three items each, on a four-point Likert scale from "never" to "often." Item factor loadings were $0.79,0.80$, and 0.84 for the depression sub-scale and $0.85,0.87$, and 0.89 for the happiness sub-scale. Total variance explained by the total scale was $70.71 \%$. CFA confirmed the two dimensional structure with a good fit $\left(\chi^{2} / \mathrm{df}=1.65\right.$, RMSEA $=0.04($ CI 90\% (0.00, 0.08)), SRMR $=0.05, \mathrm{CFI}=0.99, \mathrm{NFI}=0.98, \mathrm{GFI}=0.99$, $\mathrm{IFI}=0.99$ ). For the present study, only the depression sub-scale (e.g., "I felt that life was meaningless") was used to assess depression levels among participants. Cronbach's alpha found in study 1 for the depression sub-scale was 0.75 .

Single-Item Self-Esteem Scale (SISE) The SISE comprises one item ("I have a high selfesteem") on a seven-point Likert scale from "absolutely incorrect" to "absolutely correct." It was developed by Robins et al. (2001). Given the SISE only has one item, the Cronbach's alpha coefficient of the scale cannot be calculated. However, the original study reported that the SISE had strong convergent validity with Rosenberg's Self-Esteem Scale (Rosenberg 1965) and it has been used by many researchers around the world in order to assess selfesteem levels of participants.

\section{Statistical Analysis}

In order to show the relationships between variables descriptive, Pearson correlations and path analyses were conducted via using the SPSS 23.0 and AMOS 23.0 software applications. Normality assumptions were checked by examining the skewness and kurtosis values of the variables. Since skewness values were smaller than $|3|$ and kurtosis values were smaller than $|10|$ (Kline 2004), normal distribution was accepted. In the path analysis, the maximum 
likelihood estimation method was used. Furthermore, goodness of fit indices designated by $\mathrm{Hu}$ and Bentler (1999) were utilized. Consequently, thresholds for good and acceptable fit values are as follows: Root Mean Square Residuals (RMSEA) $<0.05$ is good, Standardized Root Mean Square Residuals (SRMR) $<0.05$ is good, Goodness of Fit Index (GFI) $>0.95$ is good, Comparative Fit Index (CFI) $>0.95$ is good, Normed Fit Index (NFI) $>0.95$ is good, and Incremental Fit Index (IFI) $>0.95$ is good; also RMSEA $<0.08$ is acceptable, SRMR $<0.08$ is acceptable, GFI $>0.90$ is acceptable, CFI $>0.90$ is acceptable, NFI $>0.90$ is acceptable, and IFI $>0.90$ is acceptable. Path analyses were carried out via using bootstrapping method with $95 \%$ bias-corrected confidence intervals and 5000 bootstrapped samples.

\section{Results}

Descriptive statistics and bivariate correlations of all study variables are presented in Table 1. CBP was moderately correlated with PSMU $(r=0.33, p<0.001)$ and weakly with depression $(r=0.19, p<0.001)$, self-esteem $(r=-0.19, p<0.001)$, and SC $(r=-0.17, p<0.001)$. PSMU was moderately correlated with depression $(r=0.37, p<0.001)$ and weakly with SC $(r=-$ $0.20, p<0.001)$ and self-esteem $(r=-0.15, p<0.001)$. Finally, depression was moderately correlated with SC $(r=-0.39, p<0.001)$ and self-esteem $(r=-0.27, p<0.001)$.

In order to demonstrate the significant direct and indirect relationships between variables, path analysis was applied. Path analysis showed that PSMU $(r=0.30, p<0.001 ; 95 \% \mathrm{CI}$ $(0.27,0.39))$, self-esteem $(r=-0.15, p<0.001 ; 95 \%$ CI $(-0.23,-0.06))$, and gender $(r=$ $0.21, p<0.001 ; 95 \% \mathrm{CI}(0.15,0.27))$ were directly related to CBP. SC $(r=-0.04, p<0.001$; $95 \% \mathrm{CI}(-0.05,-0.03))$ and self-esteem $(r=-0.02, p<0.001 ; 95 \% \mathrm{CI}(-0.03,-0.01))$ were indirectly related to CBP through depression and PSMU while depression $(r=0.10, p<0.001$; $95 \% \mathrm{CI}(0.07,0.13))$ was indirectly related to CBP via PSMU. Moreover, depression $(r=0.32$, $p<0.001 ; 95 \%$ CI $(.24,0.39))$ and gender $(r=-0.07, p<0.001 ; 95 \%$ CI $(-0.13,-0.01))$ were directly related to PSMU, while SC $(r=-0.10, p<0.001 ; 95 \% \mathrm{CI}(-0.14,-0.08))$ and self-esteem $(r=-0.04, p<0.001 ; 95 \%$ CI $(-0.07,-0.03))$ were indirectly related to PSMU via depression. While depression mediated the relationships of self-esteem (fully) and SC (fully) with PSMU, PSMU mediated the association of depression (fully) with CBP. Standardized estimates of total, direct, and indirect effects on PSMU and mediator variables and

Table 1 Descriptive statistics and Pearson correlation coefficients of the variables in study 1

\begin{tabular}{|c|c|c|c|c|c|c|c|}
\hline & 1 & 2 & 3 & 4 & 5 & 6 & 7 \\
\hline 1. CBP & - & & & & & & \\
\hline 2. PSMU & $0.33 * * *$ & - & & & & & \\
\hline 3. $\mathrm{SC}$ & $-0.17 * * *$ & $-0.20 * * *$ & - & & & & \\
\hline 4. Depression & $0.19^{* * *}$ & $0.37 * * *$ & $-0.39 * * *$ & - & & & \\
\hline 5. Self-Esteem & $-0.19 * * *$ & $-0.15 * * *$ & $0.30^{* * *}$ & $-0.27 * * *$ & - & & \\
\hline 6. Gender & $0.13 * * *$ & $-0.14 * * *$ & 0.06 & $-0.19 * * *$ & $0.17 * * *$ & - & \\
\hline 7. Age & 0.03 & $0.08 *$ & $-0.08^{*}$ & $0.17 * * *$ & -0.02 & 0.02 & - \\
\hline$\alpha$ & 0.87 & 0.83 & 0.89 & 0.75 & - & - & - \\
\hline Min & 0 & 0 & 8 & 0 & 1 & 1 & 14 \\
\hline Max & 36 & 36 & 48 & 9 & 7 & 2 & 21 \\
\hline$M$ & 3.96 & 14.35 & 38.63 & 3.75 & 5.89 & 1.52 & 16.20 \\
\hline SD & 6.30 & 7.76 & 9.00 & 2.74 & 1.55 & 0.50 & 1.03 \\
\hline
\end{tabular}

$C B P$ cyberbullying perpetration, $P S M U$ problematic social media use, SC social connectedness, Gender 1 female $* p<0.05 ; * * p<0.01 ; * * * p<0.001$ 
cyberbullying perpetration and mediator variables, respectively, are summarized in Table 2. The model predicted $22 \%$ of the depression, $14 \%$ of the PSMU, and $18 \%$ of the CBP (Fig. 2).

\section{Method (Study 2): Relationships between CBP, PSMU, GB, Depression, and Self-Esteem}

The goal of study 2 was to examine the relationships between PSMU, CBP, GB, depression, and self-esteem among university students using a structural equation model (see Fig. 1 for the hypothesized model).

\section{Participants}

In study 2, a convenience sample of 760 students from a state university, aged between 18 and 40 years $\left(60 \%\right.$ female; $M_{\text {age }}=21.48$ years, $\left.\mathrm{SD}=3.73\right)$, filled out the questionnaires voluntarily and anonymously. Researchers gathered the data by visiting each class, giving the necessary information and handing out the questionnaires to students.

\section{Measures}

The same measures used in study 1 were also used in study 2 apart from the addition of the General Belongingness Scale (GBS) instead of the Social Connectedness Scale (SCS). The GBS assesses feeling of belonging levels of university students, comprising 12 items (e.g. "I feel connected with others.") on a seven-point Likert from "absolutely disagree" to "absolutely agree." It was developed by Malone et al. (2012) and adapted into Turkish by Duru (2015) and reported optimal validity and reliability. In the present study, the scale showed high internal

Table 2 Standardized estimates of total, direct, and indirect effects on PSMU and mediator variables and cyberbullying perpetration and mediator variables, respectively, in study 1

\begin{tabular}{lcc}
\hline & Effect & \% explained of total effect \\
\hline SC $\rightarrow$ PSMU (total effect) & -0.16 & - \\
SC $\rightarrow$ PSMU (direct effect) & -0.06 & $37 \%$ \\
SC $\rightarrow$ depression $\rightarrow$ PSMU (indirect effect) & -0.10 & $63 \%$ \\
Self-esteem $\rightarrow$ PSMU (total effect) & -0.08 & - \\
Self-esteem $\rightarrow$ PSMU (direct effect) & -0.04 & $50 \%$ \\
Self-esteem $\rightarrow$ depression $\rightarrow$ PSMU (indirect effect) & -0.04 & $50 \%$ \\
SC $\rightarrow$ CBP (total effect) & -0.13 & - \\
SC $\rightarrow$ CBP (direct effect) & -0.06 & $46 \%$ \\
SC $\rightarrow$ CBP (total indirect effect) & -0.07 & $54 \%$ \\
SC $\rightarrow$ depression $\rightarrow$ CBP & -0.02 & $15 \%$ \\
SC $\rightarrow$ PSMU $\rightarrow$ CBP & -0.02 & $15 \%$ \\
SC $\rightarrow$ depression $\rightarrow$ PSMU $\rightarrow$ CBP & -0.03 & $24 \%$ \\
Self-esteem $\rightarrow$ CBP (total effect) & -0.18 & - \\
Self-esteem $\rightarrow$ CBP (direct effect) & -0.15 & $83 \%$ \\
Self-esteem $\rightarrow$ CBP (total indirect effect) & -0.03 & $17 \%$ \\
Self-esteem $\rightarrow$ depression $\rightarrow$ CBP & -0.01 & $5 \%$ \\
Self-esteem $\rightarrow$ PSMU $\rightarrow$ CBP & -0.01 & $6 \%$ \\
Self-esteem $\rightarrow$ depression $\rightarrow$ PSMU $\rightarrow$ CBP & -0.01 & $6 \%$ \\
\hline
\end{tabular}

S.E. standard error, $S C$ social connectedness, $P S M U$ problematic social media use, $C B P$ cyberbullying perpetration 


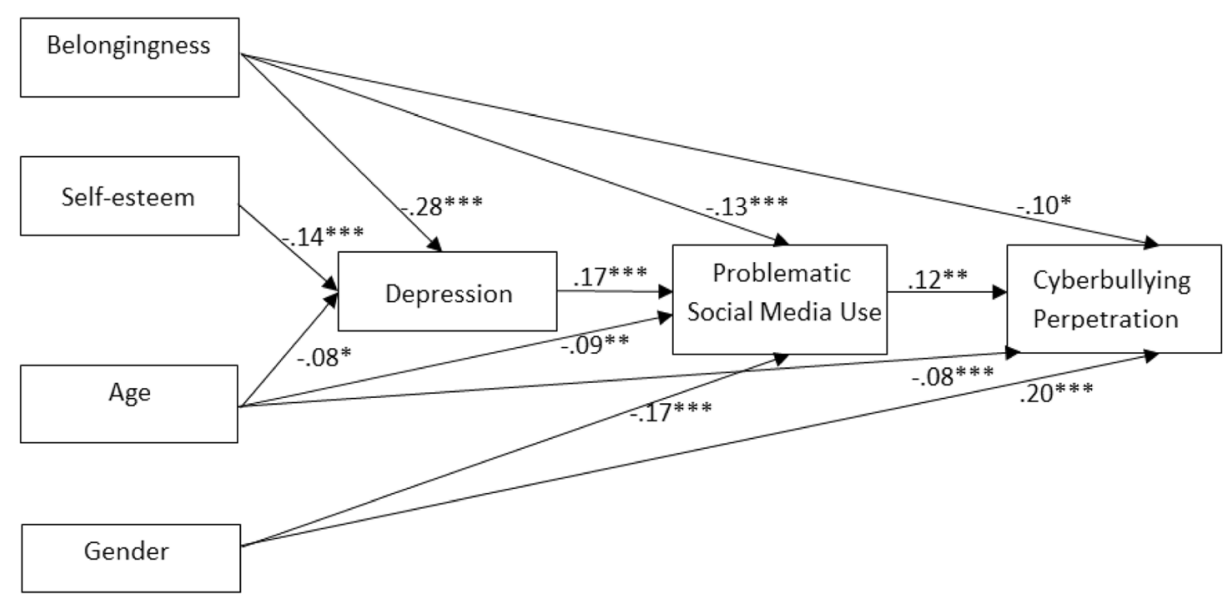

Fig. 3 Final model of the significant path coefficients of study 2. For clarity, the correlations between the four independent variables have not been depicted in the figure

consistency with a Cronbach's alpha of 0.88 . The Cronbach alphas for the scales in study 2 were 0.83 (CBOS), 0.85 (SMUQ), and 0.77 for the depression sub-scale of the SDHS.

\section{Procedure and Statistical Analysis}

Information regarding the procedure and statistical analysis in study 2 was the same as study 1.

\section{Results}

According to Pearson's correlation analysis (Table 3), CBP was weakly correlated with gender $(r=0.20, p<0.001)$, GB $(r=-0.18, p<0.001)$, PSMU $(r=0.13, p<0.001)$, depression $(r=$ $0.11, p<0.01)$, age $(r=-0.09, p<0.05)$, and self-esteem $(r=-0.09, p<0.05)$. Moreover, PSMU was weakly correlated with depression $(r=0.22, p<0.001)$, gender $(r=-0.15$,

Table 3 Descriptive statistics and Pearson correlation coefficients of the variables in study 2

\begin{tabular}{|c|c|c|c|c|c|c|c|}
\hline & 1 & 2 & 3 & 4 & 5 & 6 & 7 \\
\hline 1. CBP & - & & & & & & \\
\hline 2 PSMU & $0.13 * * *$ & - & & & & & \\
\hline $3 \mathrm{~GB}$ & $-0.18 * * *$ & $-0.10 * *$ & - & & & & \\
\hline 4. Depression & $0.11 * *$ & $0.22 * * *$ & $-0.35 * * *$ & - & & & \\
\hline 5. Self-Esteem & $-0.09^{*}$ & $-0.11 * *$ & $0.41 * * *$ & $-0.26 * * *$ & - & & \\
\hline 6. Gender & $0.20^{* * *}$ & $-0.15^{* * * *}$ & $-0.14 * * *$ & 0.01 & -0.00 & - & \\
\hline 7. Age & $-0.09^{*}$ & $-0.13 * * *$ & $-0.12 * *$ & $0.14 * * *$ & $-0.13 * * *$ & $-0.08 *$ & \\
\hline$\alpha$ & 0.83 & 0.85 & 0.88 & 0.77 & - & - & - \\
\hline Min & 0 & 0 & 13 & 0 & 1 & 1 & 18 \\
\hline Max & 31 & 35 & 84 & 9 & 7 & 2 & 40 \\
\hline$M$ & 3.01 & 14.61 & 70.05 & 4.33 & 6.00 & 1.40 & 21.48 \\
\hline SD & 5.08 & 7.37 & 12.17 & 2.66 & 1.29 & 0.49 & 3.73 \\
\hline
\end{tabular}

$C B P$ cyberbullying perpetration, $P S M U$ problematic social media use, GB general belongingness, Gender 1 female

$* p<0.05 ; * * p<0.01 ; * * * p<0.001$ 
$p<0.001)$, age $(r=-0.13, p<0.001)$, GB $(r=-0.10, p<0.001)$, and self-esteem $(r=-0.11$, $p<0.01)$. Finally, depression was moderately correlated with GB $(r=-0.35, p<0.001)$ and self-esteem $(r=-0.26, p<0.001)$.

In order to show the significant direct and indirect relationships between variables, path analysis was applied. Path analysis showed that gender $(r=0.20, p<0.001 ; 95 \%$ CI $(0.12$, $0.27)$ ), age $(r=-0.08, p<0.001 ; 95 \% \mathrm{CI}(-0.13,-0.03))$, GB $(r=-0.10, p<0.05 ; 95 \% \mathrm{CI}$ $(-0.19,-0.00))$, and PSMU $(r=0.12, p<0.01 ; 95 \% \mathrm{CI}(0.04,0.20))$ were directly related to CBP. Depression $(r=0.02, p<0.01 ; 95 \%$ CI $(0.01,0.04))$ and GB $(r=-0.03, p<0.01 ; 95 \%$ CI $(-0.06,-0.01))$ were indirectly related to CBP via PSMU. Moreover, gender $(r=-0.17$, $p<0.001 ; 95 \%$ CI $(-0.24,-0.11))$, age $(r=-0.09, p<0.01 ; 95 \%$ CI $(-0.15,-0.02))$, GB $(r=-0.13, p<0.001 ; 95 \% \mathrm{CI}(-0.20,-0.05))$, and depression $(r=0.17, p<0.001 ; 95 \% \mathrm{CI}$ $(0.09,-0.24))$ were directly related to PSMU, while GB $(r=-0.05, p<0.001 ; 95 \%$ CI ($0.08,-0.03))$ and self-esteem $(r=-0.02, p<0.001 ; 95 \% \mathrm{CI}(-0.04,-0.01))$ were indirectly related to PSMU via depression. While depression mediated the relationships of self-esteem (fully) and GB (partially) with PSMU, PSMU mediated the associations of GB (partially) and depression (fully) with CBP. Standardized estimates of total, direct, and indirect effects on PSMU and mediator variables and cyberbullying perpetration and mediator variables, respectively, are summarized in Table 4. The model predicted $14 \%$ of the depression, $10 \%$ of the PSMU, and $9 \%$ of the CBP (Fig. 3).

\section{Discussion}

The present study used the problem behavior theory (PBT) framework to examine among high school and university students how cyberbullying perpetration (CBP) and problematic social media use (PSMU) are associated with each other and to gender, age, depression, self-esteem,

Table 4 Standardized estimates of total, direct, and indirect effects on cyberbullying perpetration and mediator variables in study 2

\begin{tabular}{lcc}
\hline & Effect & \% explained of total effect \\
\hline GB $\rightarrow$ PSMU (total effect) & -0.17 & - \\
GB $\rightarrow$ PSMU (direct effect) & -0.13 & $76 \%$ \\
GB $\rightarrow$ depression $\rightarrow$ PSMU (indirect effect) & -0.05 & $24 \%$ \\
Self-esteem $\rightarrow$ PSMU (total effect) & -0.03 & - \\
Self-esteem $\rightarrow$ PSMU (direct effect) & -0.01 & $21 \%$ \\
Self-esteem $\rightarrow$ depression $\rightarrow$ PSMU (indirect effect) & -0.02 & $79 \%$ \\
GB $\rightarrow$ CBP (total effect) & -0.13 & - \\
GB $\rightarrow$ CBP (direct effect) & -0.10 & $77 \%$ \\
GB $\rightarrow$ CBP (total indirect effect) & -0.03 & $23 \%$ \\
GB $\rightarrow$ depression $\rightarrow$ CBP & -0.01 & $8 \%$ \\
GB $\rightarrow$ PSMU $\rightarrow$ CBP & -0.01 & $9 \%$ \\
GB $\rightarrow$ depression $\rightarrow$ PSMU $\rightarrow$ CBP & -0.01 & $6 \%$ \\
Self-esteem $\rightarrow$ CBP (total effect) & -0.03 & - \\
Self-esteem $\rightarrow$ CBP (direct effect) & -0.02 & $67 \%$ \\
Self-esteem $\rightarrow$ CBP (total indirect effect) & -0.01 & $33 \%$ \\
Self-esteem $\rightarrow$ depression $\rightarrow$ CBP & -0.00 & $3 \%$ \\
Self-esteem $\rightarrow$ PSMU $\rightarrow$ CBP & -0.00 & $12 \%$ \\
Self-esteem $\rightarrow$ depression $\rightarrow$ PSMU $\rightarrow$ CBP & -0.01 & $18 \%$ \\
\hline
\end{tabular}

S.E. standard error, $G B$ general belongingness, $P S M U$ Problematic Social Media Use, $C B P$ cyberbullying perpetration 
self connectedness (SC), and general belongingness (GB). According to model results, which were partially in line with the PBT, PSMU was (i) directly related to being female, being younger (only among university students sample), GB, and depression, and (ii) indirectly to self-esteem, SC, and GB via depression. Furthermore, CBP was (i) directly related to being male, being younger, GB, and PSMU, and (ii) indirectly to being male, being younger, GB, and depression via PSMU. Nevertheless, it should be emphasized that the majority of these associations, although significant, were relatively weak. Therefore, other factors - not included in the present study - are likely to play an important role in PSMU and CBP and need to be investigated in future studies.

As expected, adolescents and young adults who demonstrated higher PSMU also showed higher CBP. This finding concurs with previous studies reporting that online problem behaviors such as problematic and addictive use of Internet and CBP are related (e.g., Casas et al. 2013; Eksi 2012; Gámez-Guadix et al. 2016; Kırcaburun and Baștug 2016) and is also consistent with PBT (Jessor 1991). When all these studies are considered together, there is supporting evidence that PBT is able to explain the risky online and offline behaviors of students. This finding is important because it presents evidence that lowering PSMU may be used as an intervention method in order to prevent students from engaging in CBP. Although the results of the present study suggests that university students' problem online behaviors may be explained by the PBT, it should also be emphasized that, as expected, adolescent students' CBP was related more strongly with their PSMU when compared to university students. However, this may be due to the fact that PBT was originally proposed for adolescents.

Regarding gender, and as hypothesized, female students had more PSMU and less CBP in both samples. These results are consistent with previous studies (e.g., Andreassen et al. 2017; Festl and Quandt 2013; Kırcaburun and Tosuntaş 2017; Kokkinos et al. 2014; Slonje et al. 2012). Andreassen et al. (2013) reported that females demonstrated higher addictive behaviors among activities including social interactions. Randler et al. (2016) reported that females were more addicted to smartphones than males. Social media platforms, which facilitate social interactions, acquaintances and friendships, are easily accessible via smartphones. On the other hand, male students were more likely to be cyberbullying perpetrators, which may be explained by the fact that they are also more likely to be cyberbullying victims (Kokkinos et al. 2014). Cyberbullying victimization has been reported to be one of the strong predictors of CBP both directly and indirectly via anger (Ak et al. 2015). Moreover, Finigan-Carr et al. (2016) suggest that there are significant gender differences in types of aggressive behaviors, and that male gender is more strongly associated with aggressive and violent behaviors compared to females.

Partially in line with the hypothesis, age was negatively related to PSMU and CBP among university students but was not significant among adolescent high school students. These findings are in line with some studies (Andreassen et al. 2017; Cho and Yoo 2017) but contradict the findings of others (Hinduja and Patchin 2014). The inconsistent results may perhaps be explained by the age range of the samples used in the two studies. For instance, the high school sample was aged between 14 and 21 years, whereas the university students' ages ranged from 18 to 40 years.

The hypothesis regarding depression was partially supported. The strongest direct predictor of PSMU was depression and it was more strongly related to PSMU among high school students. This result is in line with the study of Shensa et al. (2017) which indicated that PSMU is strongly associated with increased depressive symptoms. Adolescence is a psychologically more fragile period for individuals in which depression is more commonly seen 
among students (Riglin et al. 2016) and is more positively associated with antisocial behaviors (Choi et al. 2016). Students with higher depression may be trying to cope with their vulnerable and volatile psychological states by logging online and by spending excessive time engaged in social media use. Moreover, the present study demonstrates for the first time that the association between depression and CBP was fully mediated by PSMU among both adolescents and young adults. Higher depression levels among students were associated with higher PSMU, and higher PSMU was related to higher CBP. Additionally, the present study contributes to further understanding of the relationships between self-esteem, SC, and GB with PSMU. Students with lower sense of social connectedness, belongingness, and self-esteem had higher levels of depression, which in turn, was related to higher PSMU. This result is consistent with the PBT framework of the study, which suggests that students' problem behaviors are dependent on many interrelated risk and protective factors such as individuals' personality, other psychological factors, and interactions with their social environments (Jessor 1991).

Finally, and partially in line with the hypothesis, SC was indirectly related to PSMU and CBP via depression. Furthermore, GB was found to be a significant direct and indirect predictor of both PSMU and CBP. Among young adults, students who were feeling more rejected by and isolated from their surroundings used social media more excessively and perpetrated more cyberbullying. However, adolescent students who were feeling less socially connected to their surroundings had higher levels of depression, which in turn were related to increased PSMU and CBP. According to PBT, students who have healthy and positive social relationships with their schools, families, and environmental surroundings are expected to develop and maintain fewer problematic and risky behaviors (Jessor 1991). This may also be interpreted by the negative strong correlation of GB with loneliness (Malone et al. 2012), in which higher loneliness is also reported to be positively related to PSMU (Griffiths et al. 2014). Students who feel socially isolated may spend excessive time on social media in order to compensate their need for socializing and feeling connected (Ahn and Shin 2013) and demonstrate antisocial online behaviors if they also felt rejected in online contexts.

The present study has several limitations. First, the data were collected by using self-report questionnaires. In future studies, mixed methods should be used for deeper understanding on the relationships of the variables. Second, since the nature of the study was cross-sectional, causal assumptions from the results cannot be concluded. Third, due to convenience sampling, results of this study represent only the sample of the study; therefore, more representative age and ethnic groups should be targeted in future studies for broader generalization of the findings. Finally, the majority of these associations, although significant, were relatively weak. Therefore, other factors - not included in the present study - may also play an important role in PSMU and CBP. Despite its limitations, the present study posited important new associations in understanding problematic and risky online behaviors among adolescents and young adults. In sum, the present research indicates that, consistent with PBT, students' problematic social media use is positively associated with their cyberbullying perpetration behaviors. PSMU is indirectly associated with lower social connectedness and self-esteem and directly with belongingness, depression, and being female. Furthermore, CBP is (i) indirectly associated with social connectedness, belongingness, and depression and (ii) directly with being male, belongingness, and lower selfesteem. Overall, the study highlights the important influence of depression on problematic online behaviors among students. 
Role of Funding Sources Zsolt Demetrovics was supported by the Hungarian National Research, Development and Innovation Office (Grant number: K111938, KKP126835). Orsolya Király was supported by the New National Excellence Program of the Ministry of Human Capacities. The funding organization had no role in the design or conduct of the study or the collection, management, analysis, or interpretation of the data or the preparation, review, or approval of the article.

\section{Compliance with Ethical Standards}

Conflict of Interest The authors declare that they have no conflict of interest.

Open Access This article is distributed under the terms of the Creative Commons Attribution 4.0 International License (http://creativecommons.org/licenses/by/4.0/), which permits unrestricted use, distribution, and reproduction in any medium, provided you give appropriate credit to the original author(s) and the source, provide a link to the Creative Commons license, and indicate if changes were made.

\section{References}

Ahn, D., \& Shin, D. H. (2013). Is the social use of media for seeking connectedness or for avoiding social isolation? Mechanisms underlying media use and subjective well-being. Computers in Human Behavior, 29(6), 2453-2462.

Ak, Ş., Özdemir, Y., \& Kuzucu, Y. (2015). Cybervictimization and cyberbullying: The mediating role of anger, don't anger me! Computers in Human Behavior, 49, 437-443.

Amichai-Hamburger, Y., \& Ben-Artzi, E. (2003). Loneliness and internet use. Computers in Human Behavior, 19(1), 71-80.

Andreassen, C. S., Griffiths, M. D., Gjertsen, S. R., Krossbakken, E., Kvam, S., \& Pallesen, S. (2013). The relationships between behavioral addictions and the five-factor model of personality. Journal of Behavioral Addictions, 2, 90-99.

Andreassen, C. S., Pallesen, S., \& Griffiths, M. D. (2017). The relationship between addictive use of social media, narcissism, and self-esteem: findings from a large national survey. Addictive Behaviors, 64, $287-293$.

Antoniadou, N., \& Kokkinos, C. M. (2015). Cyber and school bullying: Same or different phenomena? Aggression and Violent Behavior, 25, 363-372.

Ayas, T., Horzum, M. B., Güngören, Ö. C., Taş, İ., Kaymak, Z. D., et al. (2016). Negative effects of technology. Ankara: Vize.

Bányai, F., Zsila, Á., Király, O., Maraz, A., Elekes, Z., Griffiths, M. D., et al. (2017). Problematic social media use: results from a large-scale nationally representative adolescent sample. PLoS ONE, 12(1), e0169839.

Baumeister, R. F., \& Leary, M. R. (1995). The need to belong: desire for interpersonal attachments as a fundamental human motivation. Psychological Bulletin, 117(3), 497-529.

Bayram, N., \& Bilgel, N. (2008). The prevalence and socio-demographic correlations of depression, anxiety and stress among a group of university students. Social Psychiatry and Psychiatric Epidemiology, 43(8), 667-672.

Boyd, C. J., Young, A., Grey, M., \& McCabe, S. E. (2009). Adolescents' nonmedical use of prescription medications and other problem behaviors. Journal of Adolescent Health, 45, 539-540.

Campbell, M. A., Slee, P. T., Spears, B., Butler, D., \& Kift, S. (2013). Do cyberbullies suffer too? Cyberbullies' perceptions of the harm they cause to others and to their own mental health. School Psychology International, 34(6), 613-629.

Casas, J. A., Del Rey, R., \& Ortega-Ruiz, R. (2013). Bullying and cyberbullying: convergent and divergent predictor variables. Computers in Human Behavior, 29(3), 580-587.

Chang, F. C., Chiu, C. H., Miao, N. F., Chen, P. H., Lee, C. M., Chiang, J. T., \& Pan, Y. C. (2015). The relationship between parental mediation and internet addiction among adolescents, and the addociation with cyberbullying and depression. Comprehensive Psychiatry, 57, 21-28.

Cho, Y. K., \& Yoo, J. W. (2017). Cyberbullying, internet and SNS usage types, and perceived social support: a comparison of different age groups. Information, Communication \& Society, 20(10), 1464-1481.

Choi, T. K., Worley, M. J., Trim, R. S., Howard, D., Brown, S. A., Hopfer, C. J., et al. (2016). Effect of adolescent substance use and antisocial behavior on the development of early adulthood depression. Psychiatry Research, 238, 143-149. 
Çolak, T. S., \& Doğan, U. (2016). Does the use of social media ensure social support and happiness? International Online Journal of Educational Sciences, 8(4), 229-240.

Duru, E. (2007). An adaptation study of social connectedness scale in Turkish culture. Eurasian Journal of Educational Research, 26, 85-94.

Duru, E. (2015). The psychometric properties of the general belongingness scale: a study of reliability and validity. Turkish Journal of Psychological Counseling and Guidance, 5(44), 37-47.

Eksi, F. (2012). Examination of narcissistic personality traits' predicting level of internet addiction and cyber bullying through path analysis. Educational Sciences: Theory and Practice, 12(3), 1694-1706.

Ellison, N. B., Steinfield, C., \& Lampe, C. (2007). The benefits of Facebook "friends:" social capital and college students' use of online social network sites. Journal of Computer-Mediated Communication, 12(4), 11431168 .

Eroğlu, Y. (2016). Üniversite öğrencilerinde problemli internet kullanımı: İlișkisel-karșılıklı benlik kurgusu ve dürtüselliğin yordama güçleri. Turkish Studies, 11(3), 1091-1114.

Fan, C. Y., Chu, X. W., Zhang, M., \& Zhou, Z. K. (2016). Are narcissists more likely to be involved in cyberbullying? Examining the mediating role of self-esteem. Journal of Interpersonal Violence. https:/doi. org/10.1177/0886260516666531.

Festl, R., \& Quandt, T. (2013). Social relations and cyberbullying: the influence of individual and structural attributes on victimization and perpetration via the internet. Human Communication Research, 39, 101-126.

Finigan-Carr, N. M., Gielen, A., Haynie, D. L., \& Cheng, T. L. (2016). Youth violence: how gender matters in aggression among urban early adolescents. Journal of Interpersonal Violence, 31(19), 3257-3281.

Forest, A. L., \& Wood, J. V. (2012). When social networking is not working: individuals with low self-esteem recognize but do not reap the benefits of self-disclosure on Facebook. Psychological Science, 23(3), 295302.

Gámez-Guadix, M., Borrajo, E., \& Almendros, C. (2016). Risky online behaviors among adolescents: longitudinal relations among problematic internet use, cyberbullying perpetration, and meeting strangers online. Journal of Behavioral Addictions, 5(1), 100-107.

Griffiths, M. D., Kuss, D. J., \& Demetrovics, Z. (2014). Social networking addiction: An overview of preliminary findings. In K. Rosenberg \& L. Feder (Eds.), Behavioral addictions: criteria, evidence and treatment (pp. 119-141). New York: Elsevier.

Hagerty, B. M., Lynch-Sauer, J., Patusky, K. L., Bouwsema, M., \& Collier, P. (1992). Sense of belonging: a vital mental health concept. Archives of Psychiatric Nursing, 6(3), 172-177.

Hagerty, B. M., Williams, R. A., Coyne, J. C., \& Early, M. R. (1996). Sense of belonging and indicators of social and psychological functioning. Archives of Psychiatric Nursing, 10(4), 235-244.

Hankin, B. L., Young, J. F., Abela, J. R., Smolen, A., Jenness, J. L., Gulley, L. D., et al. (2015). Depression from childhood into late adolescence: influence of gender, development, genetic susceptibility, and peer stress. Journal of Abnormal Psychology, 124(4), 803-816.

Hinduja, S., \& Patchin, J. W. (2014). Cyberbullying glossary: brief overview of common terms. Retrieved July 17, 2017, from: https://cyberbullying.org/cyberbullying-glossary.pdf.

Horzum, M. B. (2016). Examining the relationship to gender and personality on the purpose of Facebook usage of Turkish university students. Computers in Human Behavior, 64, 319-328.

Hu, L. T., \& Bentler, P. M. (1999). Cutoff criteria for fit indexes in covariance structural analysis: conventional criteria versus new alternatives. Structural Equation Modelling, 6(1), 1-55.

Jessor, R. (1987). Risky driving and adolescent problem behavior: an extension of problem-behavior theory. Alcohol, Drugs, and Driving, 3(3-4), 1-11.

Jessor, R. (1991). Risk behavior in adolescence: a psychosocial framework for understanding and action. Journal of Adolescent Health, 12(8), 597-605.

Jose, P. E., Ryan, N., \& Pryor, J. (2012). Does social connectedness promote a greater sense of well-being in adolescence over time? Journal of Research on Adolescence, 22(2), 235-251.

Joseph, S., Linley, P. A., Harwood, J., Lewis, C. A., \& McCollam, P. (2004). Rapid assessment of well-being: the Short Depression-Happiness Scale (SDHS). Psychology and Psychotherapy: Theory, Research and Practice, 77(4), 463-478.

Jung, Y. E., Leventhal, B., Kim, Y. S., Park, T. W., Lee, S. H., Lee, M., et al. (2014). Cyberbullying, problematic internet use, and psychopathologic symptoms among Korean youth. Yonsei Medical Journal, 553(3), 826-830.

Kemp, S. (2017). Digital in 2017: Global overview. Retrieved October 8, 2017, from: https://wearesocial. com/uk/special-reports/digital-in-2017-global-overview.

Kim, K., Ryu, E., Chon, M. Y., Yeun, E. J., Choi, S. Y., Seo, J. S., \& Nam, B. W. (2006). İnternet addiction in Korean adolescents and its relation to depression and suicidal deation: a questionnaire survey. International Journal of Nursing Studies, 43, 185-192.

Kim, J. H., Griffiths, S. M., Lau, C. H., Fong, B. Y. F., \& Lam, J. (2013). Pathological Internet use and associated factors among university students in Hong Kong. Hong Kong Medical Journal, 19, 9-11. 
Kurcaburun, K. (2016). Self-esteem, daily internet use and social media addiction as predictors of depression among Turkish adolescents. Journal of Education and Practice, 7(24), 64-72.

Kırcaburun, K., \& Baștug, I. (2016). Problematic internet use as the predictor of cyberbullying tendencies among adolescents. The Journal of Academic Social Science Studies., 48, 385-396.

Kırcaburun, K., \& Tosuntaș, Ș. B. (2017). Cyberbullying perpetration among undergraduates: evidence of the roles of chronotype and sleep quality. Biological Rhythm Research, 49, 247-265. https://doi.org/10.1080 /02723646.2017.1352918.

Kircaburun, K., Alhabash, S., Tosuntaș, Ș. B., \& Griffiths, M. D. (2018). Uses and gratifications of problematic social media use among university students: a simultaneous examination of the big five of personality, social media platforms and social media use motives. International Journal of Mental Health and Addiction. https://doi.org/10.1007/s11469-018-9940-6.

Kline, R. B. (2004). Principles and practice of structural equation modeling. New York: The Guilford Press.

Kokkinos, C. M., Antoniadou, N., \& Markos, A. (2014). Cyber-bullying: an investigation of the psychological profile of university student participants. Journal of Applied Developmental Psychology, 35(3), 204-214.

Kopecký, K. (2014). Cyberbullying and other risks of internet communication focused on university students. Procedia - Social and Behavioral Sciences, 112, 260-269.

Kuss, D. J., \& Griffiths, M. D. (2011). Online social networking and addiction: a review of the psychological literatüre. International Journal of Enrironmental Research and Public Health, 8(9), 3528-3552.

Kuss, D. J., \& Griffiths, M. D. (2017). Social networking sites and addiction: ten lessons learned. International Journal of Environmental Research and Public Health, 14, 311.

Kuss, D. J., Griffiths, M. D., Karila, L., \& Billieux, J. (2014). Internet addiction: a systematic review of epidemiological research for the last decade. Current Pharmaceutical Design, 20, 4026-4052.

Lee, R. M., \& Robbins, B. S. (1995). Measuring belongingness: the social connectedness and social assurance scales. Journal of Counseling Psychology, 42(2), 232-241.

Lee, R. M., \& Robbins, S. B. (1998). The relationship between social connectedness and anxiety, self-esteem, and social identity. Journal of Counseling Psychology, 45, 338-345.

Lee, R. M., \& Robbins, S. B. (2000). Understanding social connectedness in college women and men. Journal of Counseling \& Development, 78(4), $484-491$.

Lee, R. M., Draper, M., \& Lee, S. (2001). Social connectedness, dysfunctional interpersonal behaviors, and psychological distress: testing a mediator model. Journal of Counseling Psychology, 48(3), 310-318.

Malone, G. P., Pillow, D. R., \& Osman, A. (2012). The general belongingness scale (GBS): assessing achieved belongingness. Personality and Individual Differences, 52(3), 311-316.

Moody, E. J. (2001). Internet use and its relationship to loneliness. Cyberpsychology \& Behavior, 4(3), $393-401$.

Nolen-Hoeksema, S., \& Girgus, J. S. (1994). The emergence of gender differences in depression during adolescence. Psychological Bulletin, 115(3), 424-443.

O’Connor, K. L., Dolphin, L., Fitzgerald, A., \& Dooley, B. (2016). Modeling problem behaviors in a nationally representative sample of adolescents. Journal of Adolescence, 50, 5-15.

Orth, U., Robins, R. W., \& Roberts, B. W. (2008). Low self-esteem prospectively predicts depression in adolescence and young adulthood. Journal of Personality and Social Psychology, 95(3), 695-708.

Patchin, J. W., \& Hinduja, S. (2010). Cyberbullying and self-esteem. Journal of School Health, 80(12), 614-621.

Patchin, J. W., \& Hinduja, S. (2015). Measuring cyberbullying: İmplications for research. Aggression and Violent Behavior, 23, 69-74.

Perrella, R., \& Caviglia, G. (2017). Internet addiction, self-esteem, and relational patterns in adolescents. Clinical Neuropsychiatry, 14(1), 82-87.

Radovic, A., Gmelin, T., Stein, B. D., \& Miller, E. (2015). Depressed adolescents' positive and negative use of social media. Journal of Adolescence, 55, 5-15.

Randler, C., Wolfgang, L., Matt, K., Demirhan, E., Horzum, M. B., \& Beșoluk, Ș. (2016). Smartphone addiction proneness in relation to sleep and morningness-eveningness in German adolescents. Journal of Behavioral Addictions, 5, 465-473.

Riglin, L., Thapar, A., Shelton, K. H., Langley, K., Frederickson, N., \& Rice, F. (2016). Profiling depression in childhood and adolescence: the role of conduct problems. Journal of Child Psychology and Psychiatry, 57(4), 481-490.

Robins, R. W., Hendin, H. M., \& Trzesniewski, K. H. (2001). Measuring global self-esteem: construct validation of a single-item measure and the Rosenberg Self-Esteem Scale. Personality and Social Psychology Bulletin, 27(2), 151-161.

Rosenberg, M. (1965). Society and the adolescent self-image. Princeton, NJ: Princeton University Press.

Ševčíková, A., \& Šmahel, D. (2009). Online harassment and cyberbullying in the Czech Republic: comparison across age groups. Zeitschrift für Psychologie/Journal of Psychology, 217(4), 227-229. 
Shaw, L. H., \& Gant, L. M. (2002). Indefense of the internet: the relationship between internet communication and depression, loneliness, self-esteem, and perceived social support. Cyberpsychology \& Behavior, 5(2), $157-171$.

Shensa, A., Escobar-Viera, C. G., Sidani, J. E., Bowman, N. D., Marshal, M. P., \& Primack, B. A. (2017). Problematic social media use and depressive symptoms among US young adults: a nationally-representative study. Social Science \& Medicine, 182, 150-157.

Slonje, R., Smith, P. K., \& Frisén, A. (2012). Processes of cyberbullying, and feelings of remorse by bullies: a pilot study. European Journal of Developmental Psychology, 9(2), 244-259.

Sum, S., Mathews, R. M., Hughes, I., \& Campbell, A. (2008). Internet use and loneliness in older adults. Cyberpsychology \& Behavior, 11(2), 208-211.

Tokunaga, R. S. (2010). Following you home from school: a critical review and synthesis of research on cyberbullying victimization. Computers in Human Behavior, 26(3), 277-287.

TurkStat (2016). ICT usage survey in households and individuals. Retrieved October 8, 2017, from http://www. tuik.gov.tr/PreHaberBultenleri.do?id=21779.

Valkenburg, P. M., Peter, J., \& Shouten, A. P. (2006). Friend networking sites and their relationship to adolescents' well-being and social self esteem. Cyberpsychology \& Behavior, 9(5), 584-590.

Whittaker, E., \& Kowalski, R. M. (2015). Cyberbullying via social media. Journal of School Violence, 14(1), 1119.

Woods, H. C., \& Scott, H. (2016). Sleepyteens: social media use in adolescence is associated with poor sleep quality, anxiety, depression and low sel-esteem. Journal of Adolescence, 51, 41-49.

Wu, Y. J., Outley, C., Matarrita-Cascante, D., \& Murphrey, T. P. (2016). A systematic review of recent research on adolescent social connectedness and mental health with internet technology use. Adolescent Research Review, 1(2), 153-162.

Xanidis, N., \& Brignell, C. M. (2016). The association between the use of social network sites, sleep quality and cognitive function during the day. Computers in Human Behavior, 55, 121-126.

Yen, C. F., Chou, W. J., Liu, T. L., Ko, C. H., Yang, P., \& Hu, H. F. (2014). Cyberbullying among male adolescents with attention-deficit/hyperactivity disorder: prevalence, correlates, and association with poor mental health status. Research in Developmental Disabilities, 35, 3543-3553.

Yıldırım, E. (2014). Social media psychology and digital citizens. Sağlık Düşüncesi ve Tıp Kültürü Platformu, $31,80-83$.

Young, K. S. (1998). Internet addiction: the emergence of a new clinical disorder. Cyberpsychology \& Behavior, 1(3), 237-244. 